\title{
Experimental Study of Near-Wall Liquid Film Outflow with Co-Current Gas Flow from Nozzle into Vacuum. 2. Flow Structure behind Nozzle
}

\author{
Yuri N. Vyazov, Victor G. Prikhodko, Igor V. Yarygin, Vyacheslav N. Yarygin
}

Kutateladze Institute of Thermophysics SB RAS, Novosibirsk, 630090, Russia

yarygin@itp.nsc.ru

\begin{abstract}
Outflow of a near-wall liquid film with co-current gas flow from a nozzle (cylindrical channel) into vacuum is studied experimentally. Special features of near-wall liquid films ejection into vacuum are established with the help of the developed measurement techniques (droplet phase flow structure visualization with ordinary and laser illumination, deposition of droplets on paper substrates, spectrophotometry): turn of the film in the opposite direction at the nozzle lip and its rise along the outer surface of the nozzle against gravity, cooling due to evaporation, disintegration into droplets with the formation of the spatial flow structure, which includes two typical areas: central and peripheral. The temperature of the liquid film formed on the outer surface of the nozzle is measured. It is shown that the film is cooled down to a temperature at which the pressure of liquid saturated vapors becomes equal to the pressure in the vacuum chamber. The distribution functions of droplets by size, direction of fly, and velocity in the peripheral area of the flow are obtained.
\end{abstract}

Keywords: nozzle, near-wall liquid film, co-current gas flow, outflow into vacuum, phase transition

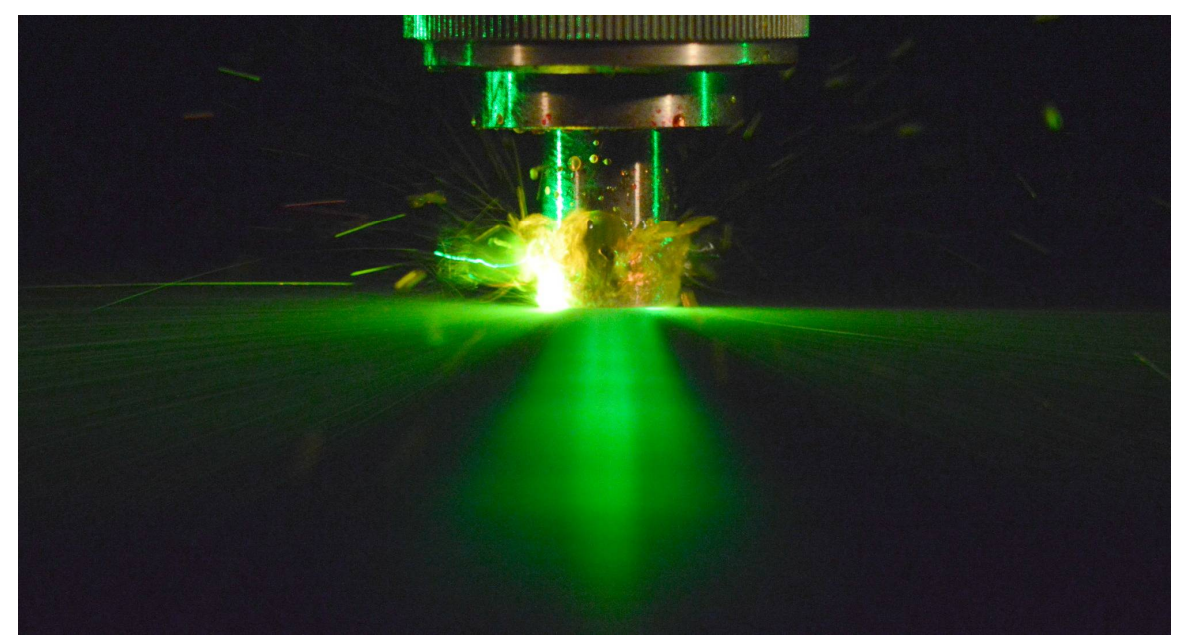

Near-wall liquid film outflow with co-current gas flow from a sonic nozzle into vacuum 


\title{
Экспериментальное исследование истечения пристенных пленок жидкости со спутным газовым потоком из сопла в вакуум. 2. Течение за срезом сопла
}

\author{
Ю.Н. Вязов, В.Г. Приходько, И.В. Ярыгин, В.Н. Ярыгин \\ ФГБУН Институт теплофизики им. С.С. Кутателазде СО РАН, \\ Россия, Новосибирск, 630090, просп. Академика Лаврентьева, д.1 \\ yarygin@itp.nsc.ru
}

\begin{abstract}
Аннотация
Экспериментально исследуется истечение пристенной пленкой жидкости со спутным газовым потоком из сопла (цилиндрического канала) в вакуум. С использованием развитых методов диагностики (визуализация структуры течения капельной фазы с обычной и лазерной подсветкой, осаждение капель на бумажные полоски, спектрофотометрия) установлены особенности истечения пристенных пленок жидкости в вакуум: разворот на выходной кромке сопла в обратном направлении и подъем по наружной поверхности сопла против силы тяжести, охлаждение за счет испарения, распад на капли с образованием пространственной структуры течения, включающей две области - центральную и периферийную. Измерены температуры пленки жидкости, образующейся на наружной поверхности сопла. Показано, что пленка охлаждается до температуры, при которой давление её насыщенных паров становится равных давлению в вакуумной камере. Измерены функции распределения капель по размерам, направлениям и скоростям в периферийной области течения.
\end{abstract}

Ключевые слова: сопло, пристенная пленка жидкости, спутный газовый поток, истечение в вакуум, фазовые превращения

\section{1. Введение}

Данная работа является продолжением [1], где были представлены результаты экспериментального исследования по взаимодействию пристенных пленок этанола, воды и смеси вода-этанол со спутным потоком воздуха внутри сопла.

Одна из особенностей проведенных исследований состояла в наличии высокоскоростного (до 300 м/с) спутного потока воздуха, который оказывал сильное динамическое воздействие на пристенную пленку жидкости, приводя к интенсивному волнообразованию, срыву капель с межфазной поверхности и их уносу. Было, в частности, показано, что количество срываемой жидкости может достигать $50 \%$ от её начального расхода и удовлетворительно коррелирует с числом Вебера спутного газового потока.

В данной, второй части работы, представлены результаты экспериментального исследования структуры течения, возникающей при истечении пристенных пленок этанола, воды и их смеси со спутным потоком воздуха из сопла в пространство, начальное давление в котором может меняться от атмосферного до 0.1 Па.

Поскольку начальное давление в вакуумной камере в условиях проведенных экспериментов (порядка 0.1 Па) существенно, на порядки ниже давления насыщенных паров этанола, воды и смеси «вода-этанол», то при истечении в вакуум эти жидкости становятся мгно- 
венно «перегретыми» даже при комнатной температуре и взрывообразно распадаются на капли с образованием пространственной структуры течения капельной фазы за срезом сопла. Конечно, это утверждение справедливо только для условий, когда давление насыщенных паров жидкостей существенно превышает давление в окружающем пространстве, как в условиях данных экспериментов, и роль фазовых превращений становится определяющей. В то же время, есть класс жидкостей с очень низким давлением насыщенных паров, например, вакуумные масла, ионные жидкости, для которых влияние фазовых переходов на поведение пленок в вакууме будет отсутствовать. Другим важным физическим свойством, определяющим поведение жидкости в вакууме, является удельная теплота испарения, что особенно ярко проявилось в экспериментах с пристенной пленкой воды.

Что касается состояния вопроса по тематике статьи, нам не удалось найти публикаций по истечению пристенных пленок жидкостей со спутным газовым потоком в вакуум. Имеющиеся публикации, в частности [2-4], посвящены истечению жидкостей (в основном воды) из трубок различного диаметра и связаны с космической тематикой.

\section{2. Экспериментальная установка и методы диагностики}

В основу методологии проведения экспериментальных исследований положено использование современных методов измерения и обработки данных по температурам пленок жидкости на внешней поверхности сопла, видеосъемки с высоким пространственным и временным разрешением процесса истечения пристенной пленки жидкости со спутным потоком газа в вакуум с использованием обычной и лазерной подсветки, а также метода спектрофотометрии для получения количественных данных по пространственному распределению капельной фазы за срезом сопла в вакууме. Экспериментальные исследования проводились на крупномасштабной вакуумной газодинамической установке ВИКИНГ ИТ СО РАН [5], позволяющей за счет большого объема вакуумной камеры $\left(150 \mathrm{~m}^{3}\right)$ проводить исследования в импульсных режимах с большими расходами жидкости и газа, недостижимыми при работе в непрерывном режиме.

В качестве источника газокапельного потока, как и первой части работы [1], было использовано изготовленное из латуни звуковое сопло с цилиндрической выходной частью внутренним диаметром 10 мм и длиной 20 мм, и имеющее форкамеру внутренним диаметром 20 мм. В части экспериментов использовалось звуковое сопло с идентичной форкамерой, такой же длины, но с внутренним диаметром 5 мм. В качестве рабочего газа использовался воздух, в качестве рабочей жидкости - в основном этанол, а также (для сравнения) вода, и их смесь с объемной концентрацией $50 \%$. Начальные температуры газа и жидкости были комнатными. Сопло устанавливалось внутри вакуумной камеры вертикально, выходным сечением вниз. Во время эксперимента вакуумная камера откачивалась до начального давления около 0.1 Па. Далее в соответствии с циклограммой эксперимента в форкамеру сопла подавался рабочий газ, затем рабочая жидкость, которая в виде пристенной пленки истекала совместно со спутным потоком из сопла в вакуум. Подача газа в форкамеру сопла осуществлялась из баллона со сжатым воздухом объемом 400 литров, установленного снаружи вакуумной камеры, и соединенного с форкамерой сопла магистралью внутренним диаметром 8 мм. На входе в форкамеру сопла был установлен электромагнитный клапан и расходная диафрагма с отверстием диаметром 1,2 или 4 мм. Подача жидкости в форкамеру сопла осуществлялась из мерной емкости, установленной снаружи вакуумной камеры и соединенной с соплом трубкой внутренним диаметром 4 мм. Использование мерной емкости позволило регистрировать расход жидкости в процессе эксперимента. В сопло жидкость попадала через электромагнитные форсунки и кольцевой зазор шириной 0.1 мм внутри форкамеры сопла для формирования равномерной пристенной пленки жидкости. Во время эксперимента сначала включалась подача газа, затем через $0.2 \mathrm{c}$ - подача жидкости, которая прекращалась спустя 3 с, еще через 1.8 с выключалась подача газа, при этом давление в вакуумной камере за время запуска поднималось на величину, не превышающую 1 Па. Мас- 
совый расход газа варьировался от 0.4 до 20 г/с (что соответствовало давлению торможения газа $P_{0}$ в форкамере сопла от 2.4 до 120 кПа), расход жидкости - от 0.3 до 2 г/с.

В процессе проведения эксперимента регистрировались такие основные параметры, как давление в вакуумной камере, давление газа в баллоне подачи, давление газа в форкамере сопла, расход жидкости. Для визуализации процесса истечения газокапельной струи, образующейся за срезом сопла, использовалась видео- и фотосъемка с помощью цифровой фотокамеры Nikon D3500. Для подсветки струи внутри вакуумной камеры применялись галогенные лампы, а также полупроводниковый лазер с длиной волны 532 нм для подсветки по методу «лазерного ножа».

Для получения количественных данных по пространственному распределению капельной фазы за срезом сопла на рабочем участке был установлен проницаемый для газового потока каркас в виде сферы радиусом $R=75$ мм, при этом центр сферы совпадал с центром выходного сечения сопла. На каркасе закреплялись узкие полоски бумаги (подложки), на которые в процессе эксперимента осаждались капли рабочей жидкости. Схема рабочего участка с установленным каркасом показана на рис. 1.

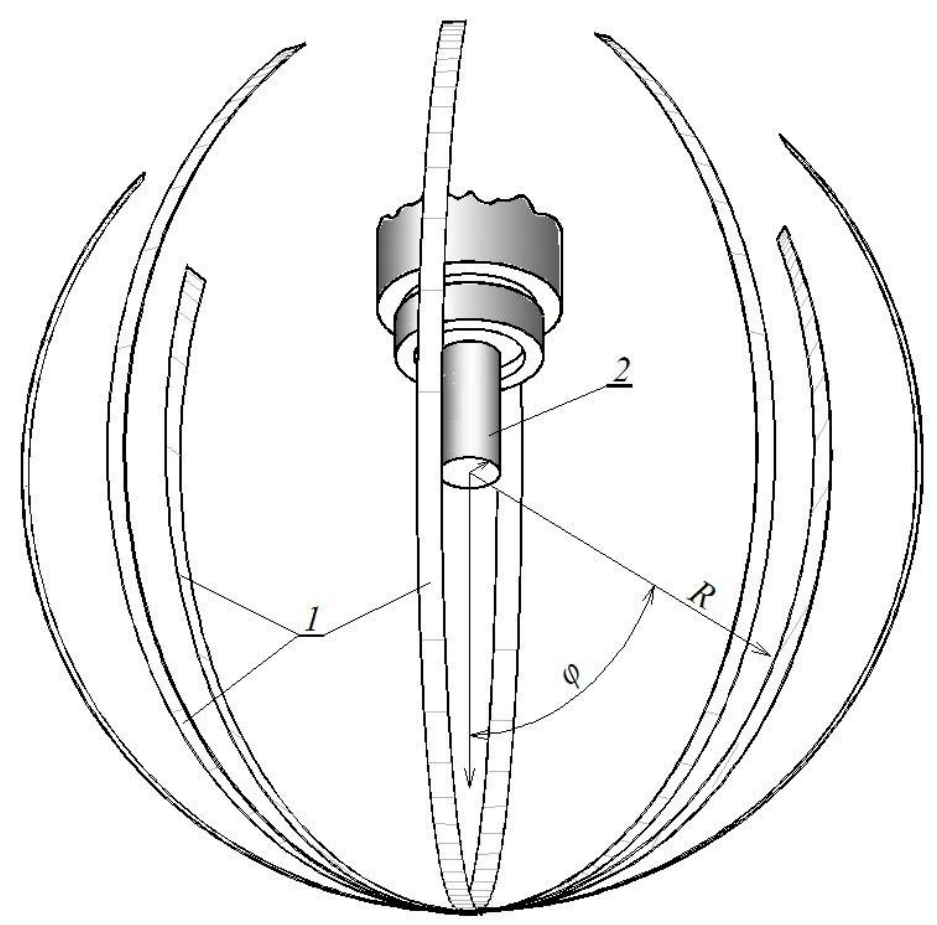

Рис. 1. Схема рабочего участка с каркасом для крепления бумажных полосок. 1 - каркас с закрепленным бумажными полосками, 2 - сопло

Одной из сложностей при диагностике газокапельных потоков, истекающих в вакуум, является быстрое испарение капель жидкости в вакууме, где обычно давление на несколько порядков ниже давления насыщенных паров жидкости. Решить эту проблему можно путем добавления в жидкость небольшого количества красителя, который не сублимируется в вакууме. В этом случае определить пространственное распределение капельной фазы можно по количеству красителя, оставшемуся на подложке после испарения жидкости. При этом для получения количественных данных требуется определение массы красителя, осевшего на разных частях бумажной подложки. В качестве красителя в работе использовался ксантеновый краситель Родамин 6Ж $\left(\mathrm{C}_{28} \mathrm{H}_{31} \mathrm{ClN}_{2} \mathrm{O}_{3}\right)$ с весовой концентрацией $0.065 \%$, который хорошо растворим как в этаноле, так и воде, а указанная концентрация не меняет физические свойства рабочих жидкостей. Для определения массы красителя был использован метод спектрофотометрии [6]. 
Другим важным вопросом при проведении исследований в рассматриваемых условиях является измерение температуры жидкости, в частности на внешней поверхности сопла после выхода пленки на срез сопла и её разворота на выходной кромке. В качестве чувствительного элемента был использован малогабаритный (размером $2.8 \times 1.2 \times 1$ мм) полупроводниковый датчик температуры Texas Instruments LM50. Выбор указанного датчика был обусловлен его малой инерционностью при достаточно высокой точности и устойчивости к электрическим помехам от работающей насосной станции вакуумной установки. Датчик температуры приклеивался с помощью термоклея на внешнюю поверхность сопла на расстоянии около 1 мм от его среза. На рис. 2 показан снимок звукового сопла диаметром $d=10$ мм с закрепленным на нем датчиком. Регистрация показаний датчика температуры, также, как и датчиков давления типа ИКД и Baratron в вакуумной камере, в форкамере сопла и магистрали подачи рабочего газа осуществлялась с помощью компьютера через установленный аналогово-цифровой преобразователь L-Card L791.

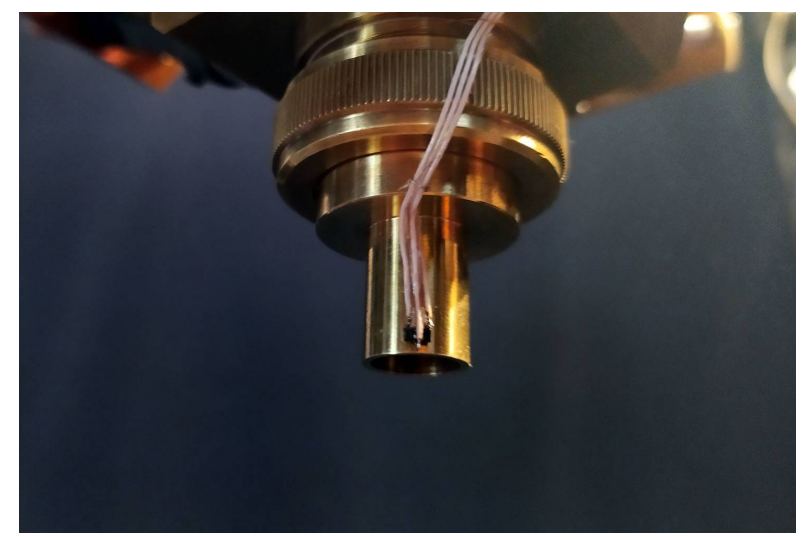

Рис. 2. Расположение датчика температуры на внешней поверхности сопла

Развитые в работе методы диагностики позволили получить достаточно полную информацию об истечении пристенных пленок жидкости со спутным газовым потоком из сопла в вакуум, включая разворот пленки на выходной кромке сопла, её подъем по наружной поверхности сопла против силы тяжести, распад на капли с формированием пространственной структуры течения капель и предельной температуре охлаждения пленки за счет фазового перехода, а также получить данные по функциям распределения капель по размерам, направлениям и скоростям. Рассмотрим полученные результаты более подробно.

\section{3. Результаты исследований и их анализ}

\section{1. Подъем пленки по наружной поверхности сопла}

На рис. 3, a, б, в приведены полученные с использованием обычной (галогенными и светодиодными лампами) фотографии процесса истечения пристенных пленок этанола, воды и смеси «вода-этанол» в вакуумную камеру при начальном давлении в ней $P_{k}=1$ Па, на pис. 3, 2- истечение пленки этанола в камеру с атмосферным давлением (картина истечения пристенных пленок воды и смеси «вода-этанол» в камеру с атмосферным давлением качественно такая же).

Число Рейнольдса пленки жидкости $\mathrm{Re}_{l}$ во всех четырех режимах было одинаковым, при этом толщина $\delta_{l}$ пленки зависела от физических свойств жидкости, в первую очередь вязкости. Видно, что процесс истечения пристенных пленок жидкостей в вакуум и в атмосферу существенно различается. При истечении в атмосферу имеет место обычная газокапельная струя, в то время как при истечении в вакуум пленка жидкости разворачивается на выходной кромке сопла, выходит на его внешнюю поверхность и поднимается вверх даже против силы тяжести. Фото, показанные на рисунке, сделаны в момент, когда высота подъ- 
ема пленки максимальна. Видно также, что при истечении в вакуум пленки воды на наружной поверхности сопла формируется слой льда, а при истечении смеси «вода-этанол» наблюдается «промежуточный» (между этанолом и водой) режим.

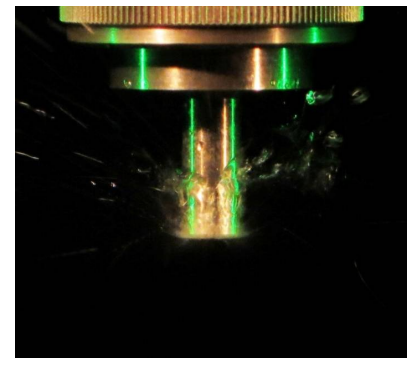

a) Этанол.

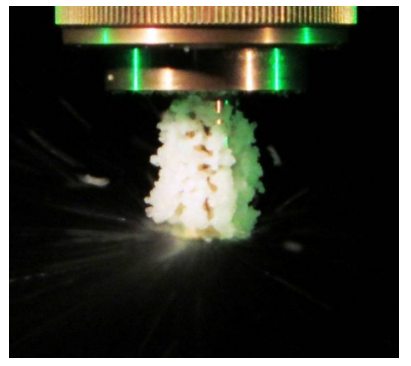

б) Вода.

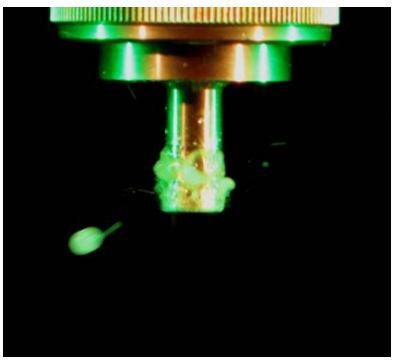

в) Смесь «вода-этанол».

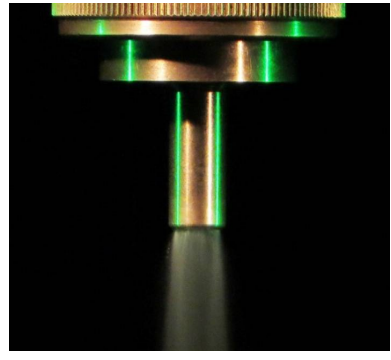

г) Этанол. $P_{k}=100 \kappa \Pi$ ка, $\delta_{l}=61$ мкм

Рис. 3. Истечение пленок жидкостей из звукового сопла в вакуум и в атмосферу. Число Рейнольдса пленки $\mathrm{Re}_{l}=20$, скорость газа на срезе сопла $V_{a} \approx 300 \mathrm{~m} / \mathrm{c}(a, \sigma, 6)$ и $180 \mathrm{~m} / \mathrm{c}$ (2)

Проведенные исследования показали, что наблюдаемый эффект (разворот и подъем пристенной пленки по наружной поверхности сопла против силы тяжести) становится практически не существенным при давлениях в камере более 10 кПа. Соответствующие экспериментальные результаты по влиянию окружающего давления на высоту подъема пленки этанола приведены на рис. 4. Видно, что в условиях проведенных экспериментов максимальная высота подъема составляет около 11 мм, и, как показали эксперименты, практически не зависит от диаметра сопла.

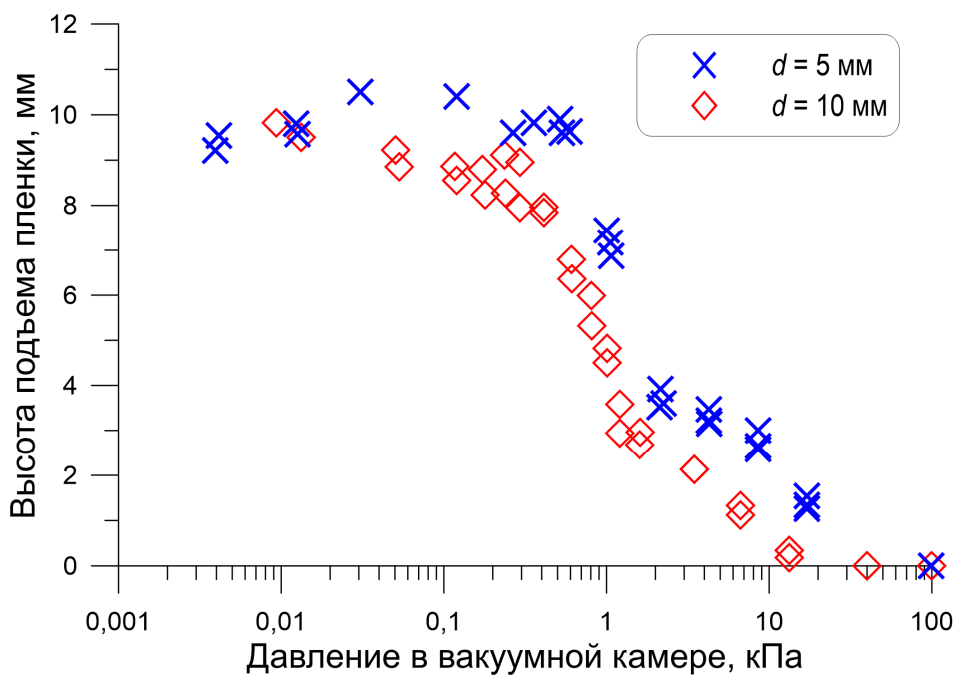

Рис. 4. Высота подъема пленки этанола при истечении из сопел диаметром $d=5$ и $d=10$ мм

Первый вопрос, который следует обсудить - какие силы в рассматриваемых условиях вынуждают пристенную пленку жидкости развернуться на $180^{\circ}$ на выходной кромке и выйти на наружную поверхность сопла? Второй вопрос - какие силы заставляют пленку жидкости двигаться вверх по наружной поверхности сопла даже против силы тяжести? Известно, что при расширении газа из сопла в вакуум возникает течение Прандтля-Майера, в котором газовый поток разворачивается на угол более $90^{\circ}$ относительно оси струи. Предельный угол разворота $\Theta_{\max }$ зависит от числа Маха $\mathrm{M}_{a}$ и отношения удельных теплоемкостей $\gamma=c_{p} / c_{v}$ и для нашего случая $\left(\mathrm{M}_{a}=1, \gamma=1.4\right)$ составляет $\Theta_{\max }=130^{\circ}$, т.е. возникают обратные потоки газа. По-видимому, этот разворачивающийся газовый поток удерживает пленку на выходной кромке сопла и заставляет её выходить на наружную поверхность 
сопла. В то же время, вследствие сильного (на порядки) падения плотности газа при расширении в вакуум величина касательного напряжения $\tau=\left(C_{f} / 2\right) \rho V^{2}$ (где $C_{f}-$ коэффициент сопротивления; $\rho$ - плотность газа; $V$ - скорость газа) также сильно, на порядки, уменьшается, и воздействие газового потока на пленку практически прекращается. Поэтому, если разворот пленки жидкости на кромке сопла за счет взаимодействия с газовым потоком выглядит правдоподобным, то её подъем по наружной поверхности сопла за счет этого механизма маловероятен.

Можно предположить, что существует ряд факторов, обуславливающих подъем пленки вверх против силы тяжести, в частности лапласово давление на поверхности пленки при обтекании кромки сопла, а также инерционные силы пленки. В случае влияния лапласова давления на высоту подъема не должно наблюдаться сильной зависимости высоты от давления в окружающем пространстве, однако результаты экспериментов говорят об обратном (см. рис.4). Рассмотрим более подробно влияние инерционных сил пленки жидкости на её подъем по наружной поверхности сопла. Из уравнения сохранения энергии можно оценить максимальную высоту подъема пленки жидкости

$$
h=\frac{V_{l}^{2}}{2 g},
$$

где $V_{l}$ - скорость пленки жидкости в выходном сечении сопла; $g$ - ускорение свободного падения. Тогда при измеренной [1] скорости движения пленки этанола $V_{l}=0.6 \mathrm{~m} / \mathrm{c}$ максимальная высота подъема пленки на наружной поверхности составит $h_{\max }=18$ мм, что коррелирует с экспериментальным значением (11 мм, см. рис. 4). В то же время истинная скорость движения пленки после её выхода на наружную поверхность сопла и скорость подъема неизвестны. Можно ожидать, что из-за сопротивления при движении вверх по стенке она должна быть несколько меньше. Поэтому предложенный механизм подъема пленки на данном этапе исследований кажется правдоподобным, однако этот вопрос, на наш взгляд, требует дальнейших исследований.

В заключение данного раздела рассмотрим более подробно результаты экспериментов со смесью «вода-этанол» с объемной концентрацией 50\%. На рис. 5 приведены фотографии процесса истечения пристенной пленки смеси «вода-этанол» при истечении в вакуумную камеру при различном давлении в ней.

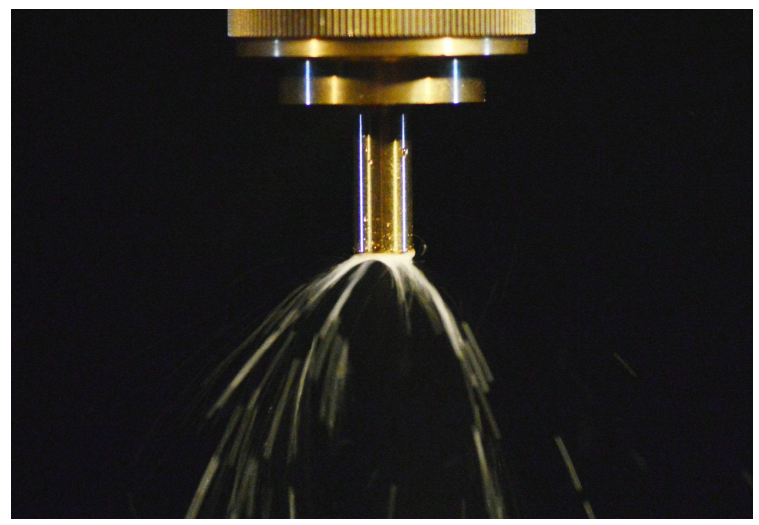

a) $P_{k}=3200$ Па

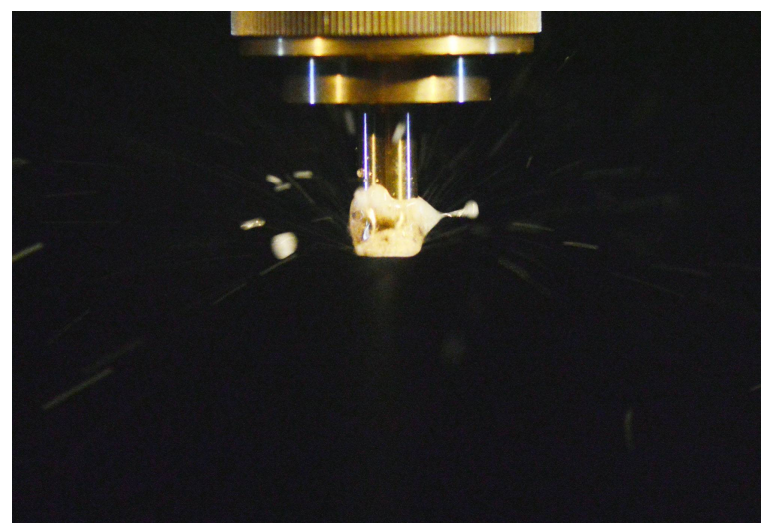

б) $P_{k}=70$ Па

Рис. 5. Истечение пристенной пленки смеси «вода-этанол» в вакуумную камеру с различным давлением $P_{k}$ в ней

При истечении в пространство с высоким окружающим давлением (от атмосферного до примерно 50 кПа) пленка жидкости диспергируется на мелкие капли, которые летят вдоль оси сопла, формирую газокапельный поток (аналогично истечению пленник этанола, см. рис. 3,2$)$. По мере уменьшения давления в вакуумной камере жидкость начинает выхо- 
дить на наружную поверхность канала, образуя на ней сплошную пленку (рис. 5, a). При этом меняется и режим разлета жидкости, а именно капли перестают быть прозрачными, что, по-видимому, говорит о начале процесса испарения и кристаллизации жидкости. Поскольку смесь «вода-этанол» с объемной концентрацией 50 \% не является азеотропной, то процесс испарения смеси начинается с компонента, у которого выше давление насыщенных паров, а именно этанола. В процессе испарения смеси концентрация воды в ней становится выше, температура жидкости уменьшается и начинается процесс её замерзания. При этом на кадрах капли жидкости становятся непрозрачными. В дальнейшем высота подъема пленки по наружной поверхности канала увеличивается, а капли, разлетающиеся с кромки, становятся крупнее. При давлении в вакуумной камере порядка 1 кПа и ниже начинается процесс взрывообразного разрушения пленки жидкости на внешней стороне канала, в результате которого с поверхности пленки начинается разлет мелких капель на углы более $90^{\circ}$ относительно оси сопла (рис. 5б).

\section{2. Предельная температура охлаждения пленок на наружной поверхности сопла}

Проследим далее за поведением пленок жидкости, формирующихся на наружной поверхности сопла. Из общих соображений ясно, что пленки исследуемых жидкостей при попадании в вакуум должны испаряться, а их температура понижаться. На рис. 6 приведены результаты измерения температуры датчиком, расположенным на внешней поверхности сопла вблизи его выходного сечения, для воды, этанола и их смеси при истечении в атмосферу (рис. $6, a)$ и в вакуум (рис. 6,6 ).

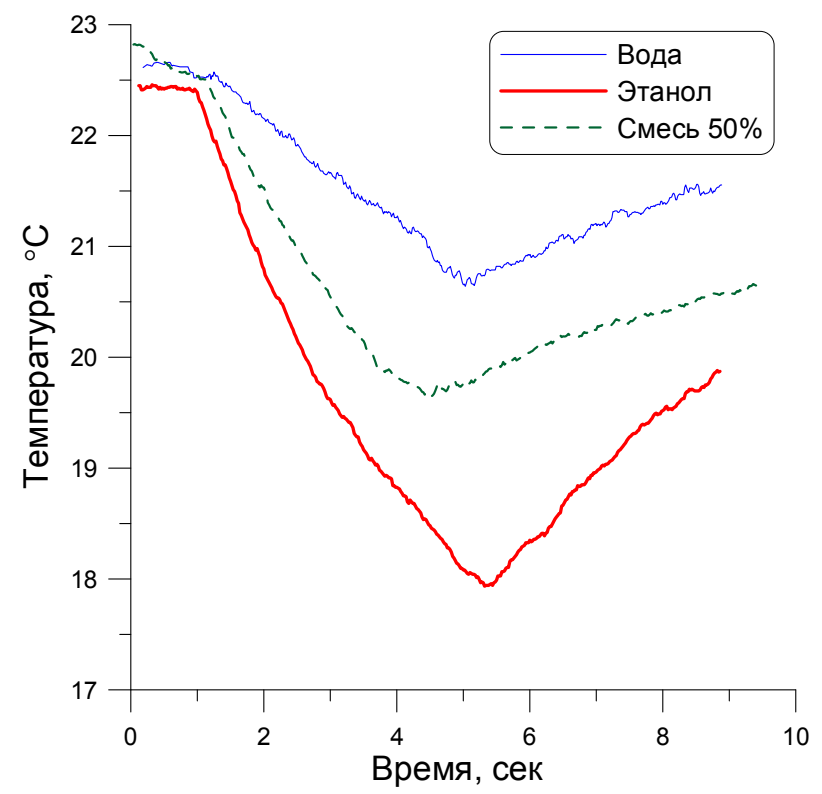

a) Истечение в атмосферу $\left(P_{k}=100\right.$ кПа)

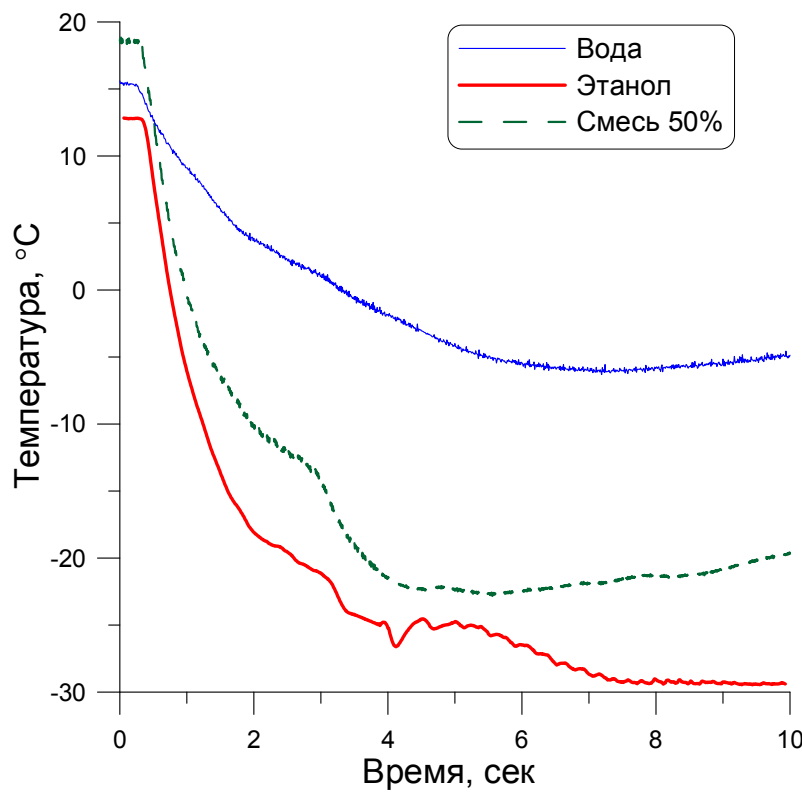

б) Истечение в вакуум ( $P_{k}=1$ Па)

Рис. 6. Температура на внешней поверхности канала. $\operatorname{Re}_{g}=4 \times 10^{4}$

Из рис. 6 можно видеть, что за время импульса (от 1.5 до 6.5 с при истечении в атмосферу и 0.5 до 5.5 с при истечении в вакуум) происходит охлаждение пленки. Было установлено, что конечная температура пленки при истечении в атмосферу на несколько градусов ниже начальной температуры и зависит от числа Рейнольдса спутного газового потока $\operatorname{Re}_{g}$. При истечении в вакуум ситуация радикально меняется, а именно пленка этанола охлаждается до температуры, при которой давление насыщенных паров этанола близко к давлению в вакуумной камере, т.е. чем ниже давление в вакуумной камере, тем сильнее охлаждается пленка жидкости. Что касается истечения пристенной пленки воды в вакуум, то наблюдается её практически мгновенное замерзание на внешней поверхности канала, 
при этом предельная температура охлаждения составляет около $-5^{\circ} \mathrm{C}$ и не зависит от давления в вакуумной камере. При истечении пленки смеси «вода-этанол» из сопла в вакуум, как отмечалось выше, сначала наблюдается разворот пленки на кромке и её движение в обратном направлении, как и для этанола, но спустя несколько секунд начинается процесс её кристаллизации. При этом предельная температура охлаждения пленки смеси выше, чем для пленки этанола, но ниже, чем для пленки воды.

\section{3. Пространственная структура течения капельной фазы за срезом сопла и функции распределения капель по размерам, направлениям и скоростям}

Для получения пространственной структуры течения капельной фазы жидкость, как отмечалось ранее, подкрашивалась небольшим количеством красителя Родамин 6Ж, что позволило определить массу осевших на подложки капель. В качестве примера на рис. 7 представлен типичный вид бумажной полоски с осевшими каплями при использовании в качестве рабочей жидкости этанола для режима истечения с числом Рейнольдса газа близким к максимальному $\left(\operatorname{Re}_{g}=1.55 \times 10^{5}\right)$. Результаты спектрофотометрирования этой полоски представлены на рис. 8 .

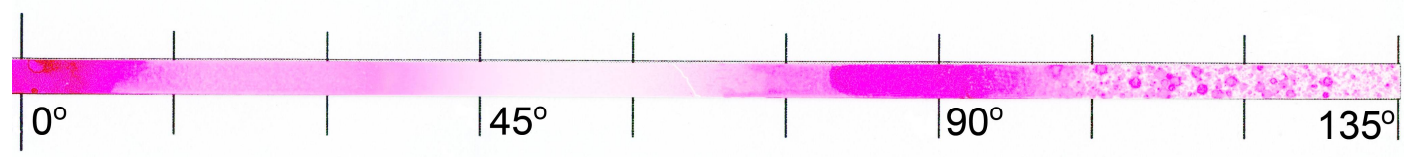

Рис. 7. Пример бумажной полоски с осевшими каплями

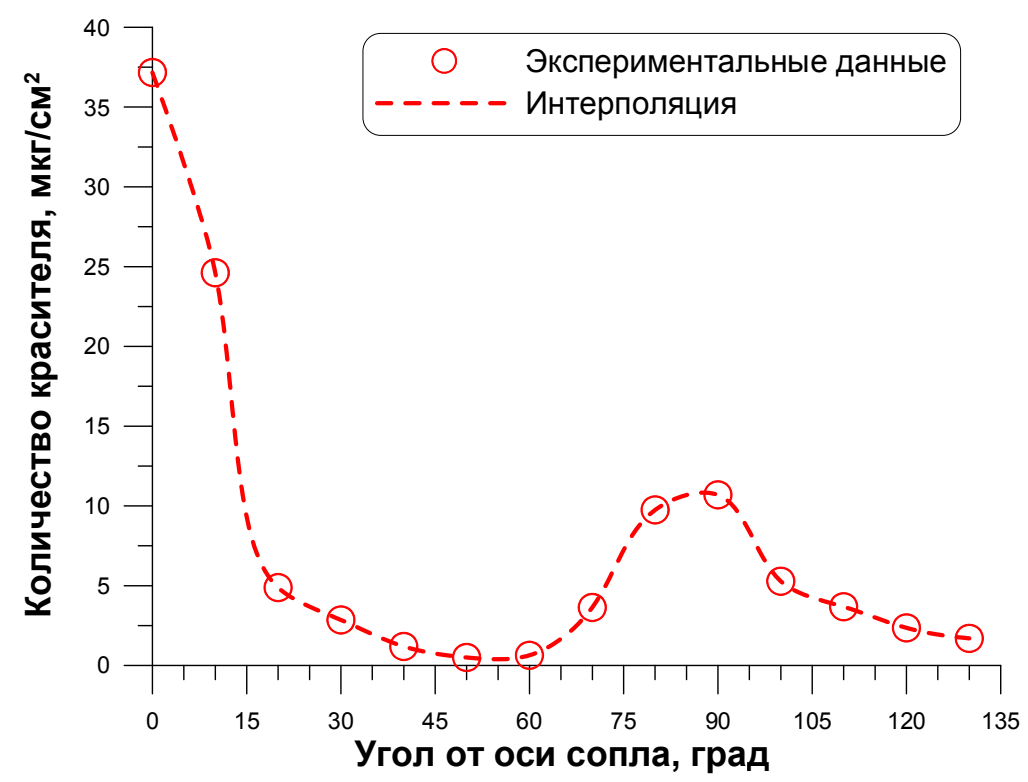

Рис. 8. Результаты спектрофотометрирования бумажной полоски

Прокомментируем представленные результаты. Обратимся сначала к бумажной полоске. Видно, что угловое распределение капельной фазы неоднородно: наиболее интенсивно окрашена приосевая зона и зона под углом около $90^{\circ}$ относительно оси струи. Видно также, что в приосевой зоне окраска равномерная, в то время как в периферийной зоне можно наблюдать следы от отдельных крупных капель. Таким образом, из рассмотрения этих данных можно говорить о формировании двух характерных областей течения капельной фазы за срезом сопла в вакууме. Центральная (приосевая) зона формируется из капель, срываемых высокоскоростным спутным потоком газа внутри сопла с межфазной поверхности. При этом количество срываемых капель с поверхности пленки, как было показано ранее [1], может достигать $50 \%$ от начального расхода жидкости. Срываемые капли дробятся 
и ускоряются спутным потоком и за срезом сопла формируют высокоскоростной мелкодисперсный поток капель в приосевой зоне. Периферийная зона формируется из пристенной пленки жидкости, достигшей среза сопла. Эти капли относительно крупные и низкоскоростные. Сказанное подтверждает рис. 8 , на котором представлены результаты обработки бумажной полоски с использованием метода спектрофотометрии для получения количественных данных о массе осевших капель. Здесь также прослеживается наличие двух характерных областей капельной фазы. Предложенная методика позволила определить суммарный расход прилетевших на подложки капель и после суммирования по всей сфере сравнить с начальным расходом жидкости через сопло. Оказалось, что суммарная масса капельной фазы, определенная по результатам эксперимента, лишь на 8 \% меньше начального расхода жидкости, что свидетельствует о достаточно высокой точности предложенной методики.

Использование лазерной подсветки («лазерного ножа») подкрашенной Родамином жидкости (этанола) позволило получить более четкую картину истечения пристенной пленки жидкости со спутным газовым потоком из сопла в вакуум, а также получить функции распределения капель по размерам, направлениям и скоростям в периферийной области течения, где капли относительно крупные. Соответствующие результаты приведены на рис. $9-12$.

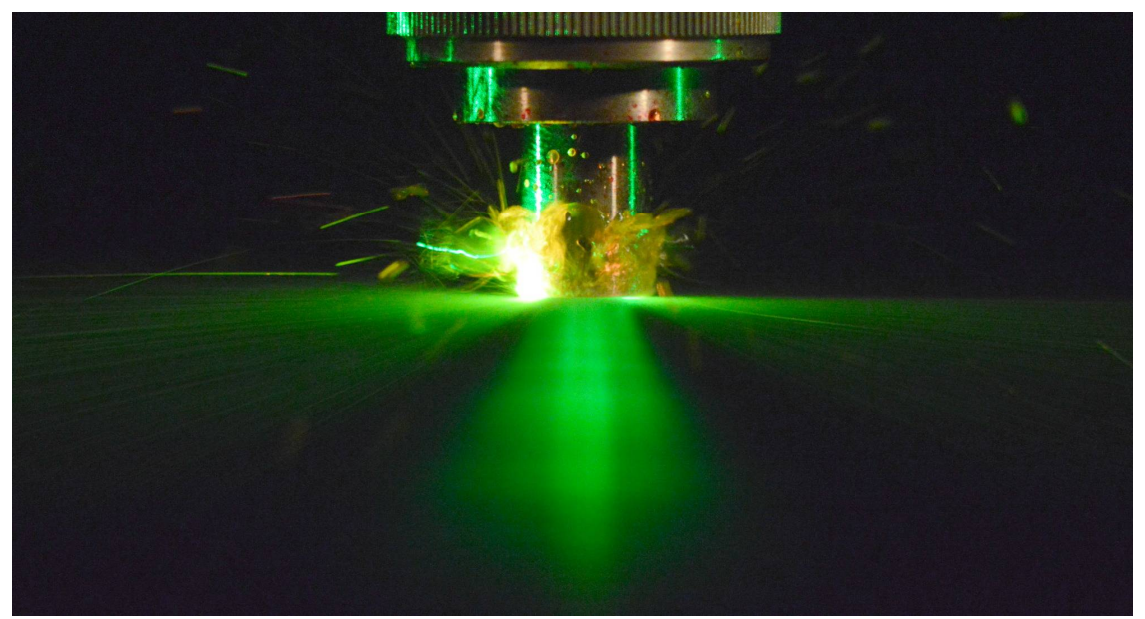

Рис. 9. Истечение пристенной пленки этанола из сопла в вакуум

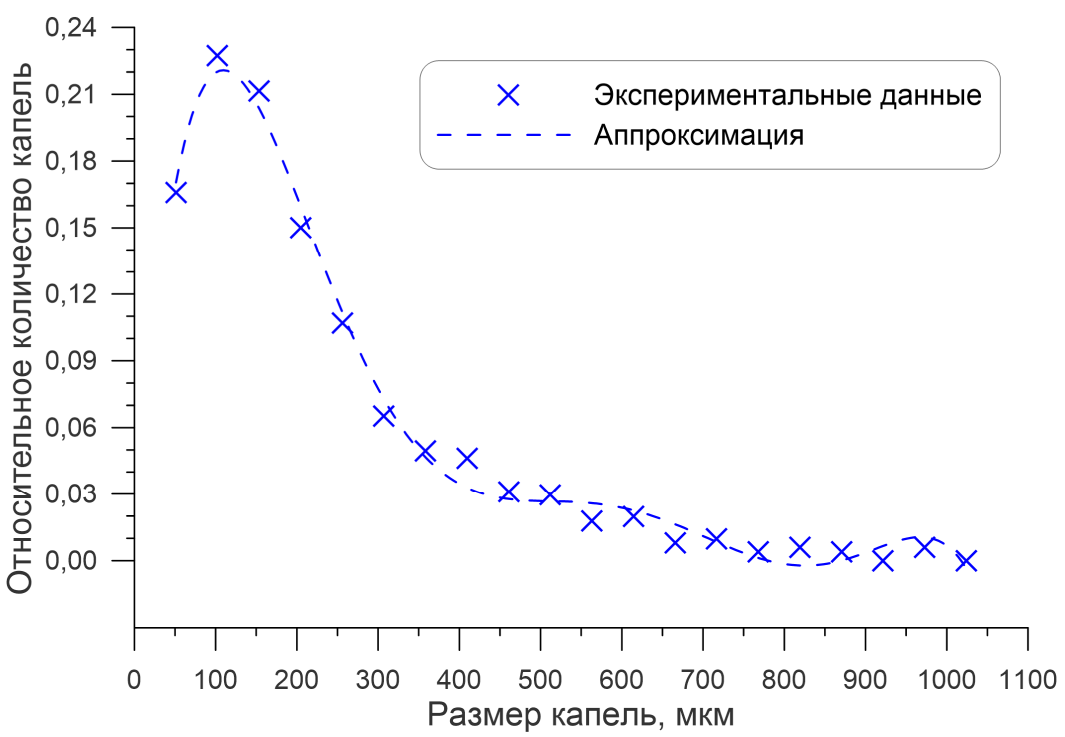

Рис. 10. Распределение капель по размерам, этанол 


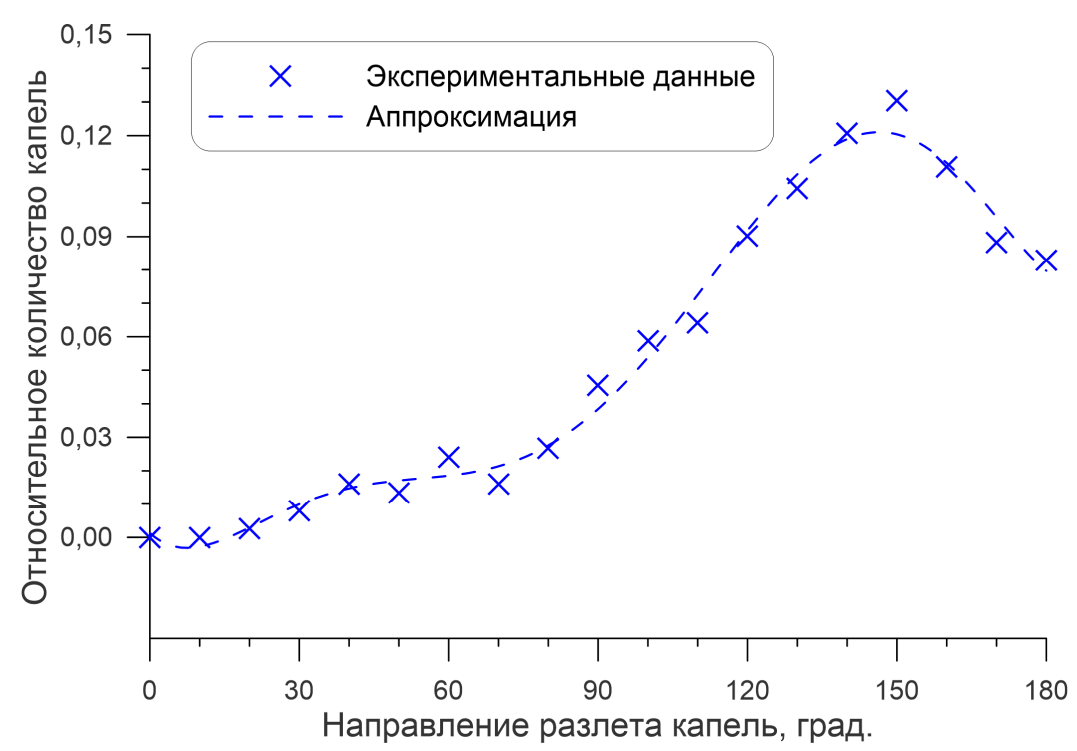

Рис. 11. Распределение капель по направлениям, этанол

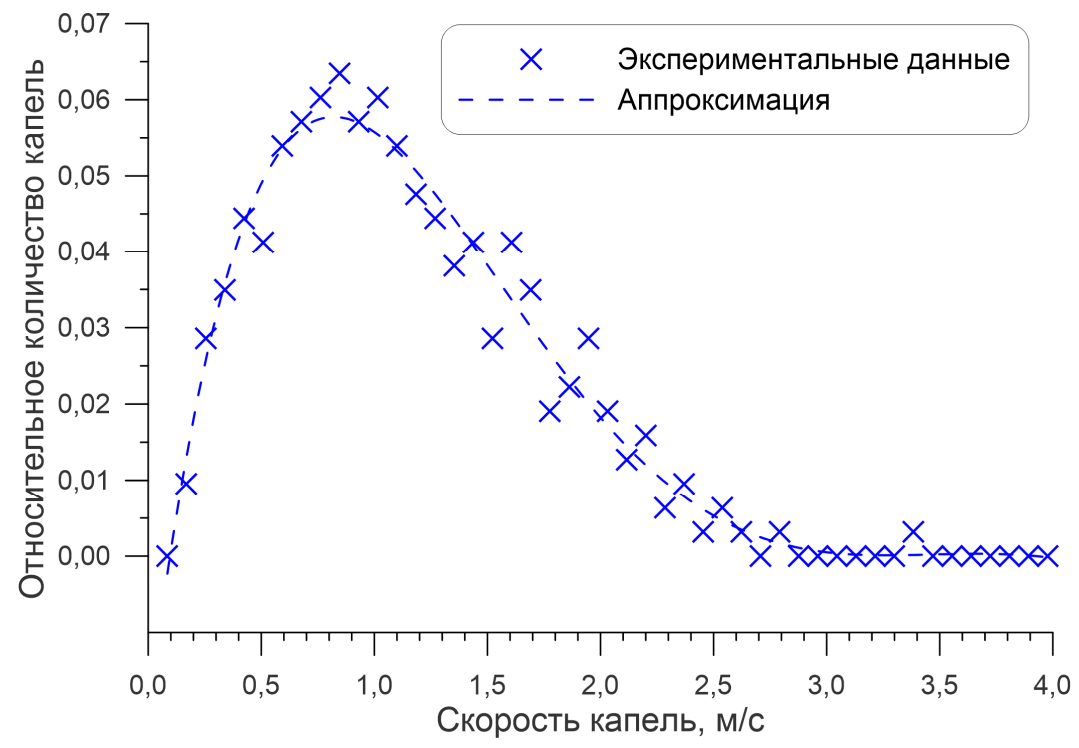

Рис. 12. Распределение капель по скоростям, этанол

Можно видеть, что функции распределения капель по скоростям вполне коррелирует с полученными ранее [1] скоростями движения пристенной пленки жидкости внутри сопла. Что касается общей структуры течения по представленные результаты (рис.9) также подтверждают формирование двух характерных зон течения капельной фазы за срезом сопла в вакууме: центральной и периферийной.

\section{4. Заключение}

Выполнен цикл экспериментальных исследований по истечению пристенных пленок воды, этанола и их смеси со спутными потоком воздуха из сопла (цилиндрического канала) в вакуум. Показано, что определяющее влияние на характер и особенности истечения пристеных пленок в вакуум оказывают предыстория течения пристенной пленки жидкости внутри сопла (её взаимодействие с высокоскоростным потоком газа), физические свойства жидкостей (в первую очередь давление насыщенных паров и удельная теплота испарения), величина давления в окружающем пространстве (в вакуумной камере). Показано возникновение возвратного движения пристенной пленки жидкости по наружной поверхности сопла и образование двух характерных областей течения капельной фазы: центральной и перифе- 
рийной. Предложены механизмы их возникновения. Показана роль фазовых переходов в установлении предельной температуры охлаждения пленок, формирующихся на наружной поверхности сопла.

Полученные экспериментальные результаты могут быть использованы для тестирования разрабатываемых моделей истечения пристенных пленок жидкостей со спутным газовым потоком из сопел в вакуум.

\section{Литература}

1. Вязов Ю.Н., Приходько В.Г., Ярыгин И.В., Ярыгин В.Н. Экспериментальное исследование истечения пристенных пленок жидкости со спутным газовым потоком из сопла в вакуум. 1 . Взаимодействие внутри сопла // Физико-химическая кинетика в газовой динамике. 2018. Т.19, №1. http://chemphys.edu.ru/issues/2018-19-1/articles/728/ DOI: 10.33257/PhChGD.19.1.728

2. Mikatarian R.R., Anderson R.G. An Experimental Investigation of a Liquid Jet Expelled into a Vacuum. // J. of Spacecraft and Rockets. 1966. Vol.3. - P. 267.

3. Fuchs H., Legge H. Flow of a Water into Vacuum//Acta Astronautica. 1979. Vol.6. - Pp. 1213-1226.

4. $\quad$ Alred J.W., Smith L.N., Wang K.C., Lumpkin F.E., Fitzgerald S.M. Modelling of Water Injection into Vacuum // Proc. Eighth Annual Thermal and Fluids Analysis Wokshop. Spacecraft Analysis and Design. 1997. Houston, Texas.

5. Приходько В.Г., Храмов Г.А., Ярыгин В.Н. Крупномасштабная криогенно-вакуумная установка для исследования газодинамических процессов // Приборы и техника эксперимента. 1996. № 2. - C. 162-164.

6. V.G. Prikhodko, I.V. Yarygin, Yu.N. Vyazov. Spectrophotometry technique for droplet phase spatial distribution measurements in gas-droplet flow behind a supersonic nozzle in a vacuum // Interfacial Phenomena and Heat Transfer. 2019. Vol. 7, Iss. 2. - Pp. 105-111. DOI:

10.1615/InterfacPhenomHeatTransfer.2019031185

Статья поступила в редакцию 21 ноября 2019г. 